\title{
Coinage and Neologism in Hausa Political Programs: A Sociolinguistics Perspective
}

\author{
Abdulkadir Abubakar Zailani \\ Department of Nigerian Languages and Linguistics \\ Kaduna State University, \\ Kaduna- Nigeria \\ abdulkadirzailani@yahoo.co.uk
}

DOI: https://doi.org/10.18326/rgt.v12i2.238-252

\section{Submission Track:}

Received: 09-02-2019

Final Revision: 21-11-2019

Available online: 01-12-2019

\begin{abstract}
Linguistic aspect of language development is not an event that occur abruptly; rather, it pass through processes that take place gradually over time, in a stage by stage development. This paper dwells on linguistic issues on coinage and neologism arising in Hausa political programs in the media (radio), from the sociolinguistic perspective, which gave birth and rebirth of words/phrases meaning. New words/phrase are created, the existing ones are lexically and semantically expanded to accommodate new meanings in Hausa language usage. It observes and explains how some Hausa lexical items as well as sentences are used in the media (radio) political programs in such a way that the language has new words and meanings; and instances of coinage and neologism in Hausa in the media are discussed.
\end{abstract}

Keywords: Coinage \& neologism, Hausa political programs, Sociolinguistics 


\section{INTRODUCTION}

The speakers of a language can coin new words according to their needs with the help of already existing words or word-forming elements in the language. Hausa as a language do coin new words, and the language is one of the three major Nigerian languages others are the Yoruba and Igbo. The language is widely accepted and used as lingua-franca by many people from different ethnic groups in northern Nigeria. Furthermore, the language is also been used across Nigeria and West Africa. It is used in both print and non-print media houses. That is in newspapers and radio stations for news broadcast, education, entitlements, political programs and a host of others. Hausa language has served as a tool which radio use for social engineering and mobilization. It has long been the language of politics, religion (Islam and Christianity alike) and broadcasting before Nigerian independence and after independence. The language almost up to date is the Nigerian language that enjoys the highest patronage of Western media stations especially the BBC, VOA, RFI, DW and a lot of others. It is also in Hausa that the media assessed and evaluate the performance of the elected representatives and the elected public office holders for the benefit of the electorates. An example of such programs is on the Hausa radio station across the Northern region of Nigeria, "An ce, ka ce" of Nagarta Radio Kaduna, and the likes.

Mohsin (2013:1) argues that the amount of newly generated information that we utilize in our daily lives far surpasses the accumulative amount of information that we produced in past generations. Therefore, we need to create or coin a huge number of new labels and names for everything new that has come into existence in recent times. 
Therefore, this paper attempts to view the existence of new words/phrases created by politicians and presenters for different purposes and motives in radio political programs specifically, the Nagarta Radio Hausa political program. "An ce, Ka ce". That made the meaning of the word shifts away from its primary senses to acquire multiple senses. However, it studies coinage and neologism as the process of word creation and extension in meaning of words and phrases, which develops new words in the language by the users, particularly because radio has great influence and appeal on them.

\section{RESEARCH METHODS}

Inventing new words is especially reflected in language as needs of society in terms of new concepts and ideas, constantly arising from the development of science, technology, culture, public relations, politics, etc. Coinage and neologisms reflect the socio-cultural situation in Hausa political programs too. In this way to identify the coinage and neologisms and its process, the data was taken from the Hausa political program in a Northern Nigeria Radio "Nagarta Radio". This means that data were gathered from primary and secondary sources, which include; observations at participants and not participants' level, in the radio political program.

The selection of this political program is due to the high number of coining new words in the program, and also high number of listeners of the program. This will make data acquisition easy to collect due to the above factors. It is likely that people have encountered new words in the program due to their exposure and interaction with the program. 
The program is broadcast from Monday to Friday of every week, and those programs presented in year 2015 and 2019 were selected through purposive sampling. Among these, 2015 and 2019 were years for Nigerian general elections. This was informed by the fact that political activities were high and would help trace any change in language that may be experienced by the listeners and presenters of the program. The researcher also listen the program on regular basis.

\section{RESULTS \& DISCUSSIONS}

\section{Language, Media (Radio) and Politics}

According to Gabari (2012) radio is the major medium of disseminating information to a large number of people no matter the distance. Human language is most exacting and demanding. It deals with the formal theories about the linguistic knowledge human beings need, for generating and understanding language. Poret (2009:14) notes that media in the past hard greatly helped in reviving democracy when it successfully, in partnership with other civil society groups exterminated military rule in the country. Nigeria today has many electronic and print media houses and stations, through which the voice of the masses could be heard. However, Cheggs (1960) states that mass media consists of the various means by which information reaches people such as television, radio, movies, newspapers and the internet. Mass media is one of the great agents of change in any ideal society. It influences the general thinking of the populace, educated and non-educated (Balarabe, 2013:15).

Mukhtar (2004:108) argues that, the manipulation of sentence by the media can be seen as intentional with a view to achieving particular purpose or 
effect. In most cases, the purpose is to attract attention of readers and front page headlines or lead stories are particularly structured in such a way to achieve that effect.

Language and political campaign indeed are synonymous, because campaign can not be carried out without a language a persuasive language for that matter. In support of this assertion, Sani (2011:47) argues that political campaign is a persuasive communication aimed at mobilization of support and influencing action. Campaign therefore, denotes the activities of an individual or group in a particular context designed to manipulate the behavior of a wide number of people.

The primary role of political language is to solicit response and preserve relationship among people. The rejuvenation and revitalization of Hausa political words has taken a new dimension beside the traditional process of word formation. The word formation devices of compounding derivative and affixation, traditionally has to do with the form of the word itself, whereas the coinage and neologism are concurrently, dealing with the meaning of the word sense. Really, in no small measure, the expansion of political terms has been a breakthrough in the field of linguistics (Abba, 2013:120).

However, Gandu (2014) argues that Hausa political graphics contain images and inscribed messages on paper, fabric, leather, polyester products, panels, screens and flat surfaces. The graphics are important infrastructure or media through which political metaphors are used as linguistic resources for the attainment of political objectives. 


\section{Coinage and Neologism in Radio (Media)}

Neologisms or coinage is one of the processes of creating new words. In the media, journalists often coin new expressions with the help of different word formation processes (compounding, shortening, hybridization, claque and affixation etc). People try to outdo each other with more attractive and unique expressions to name their products, which results that these trademarks names are adopted by the common person and become "everyday words of language" (Yule 2006, 53).

Coinage is the method of creating new words or phrases. The coined items are puts to use by the Speech Community. Similarly, new concepts and ideas are coming into the body of the existing lexicon. However, coinage is a process whereby new words are totally invented to name objects, ideas or concepts (Nasir 2008:52 in Abba 2013:117).

This is in line with, Safire (1978) opinion where Sani (2011:33) notes that two types of coinages do exist: Chorus and Phantom. Chorus coinage is where a word or phrase pops into political language without recoverable coiner while the Phantom is where a coinage enters the language by osmosis. Though some words and phrases have been in the Hausa lexicon, by the coming of modern politics, it pops into political discourse and took several interpretations. For strong political culture of the people, the words and phrases became a political language that electorates reckon with.

Neologisms tend to occur more often in cultures that are changing rapidly and also in situations where there is easy and fast propagation of information. 
The new terms are often created by combining existing words or by giving words new and unique suffixes or prefixes.

After being coined, a newly coined word invariably undergoes scrutiny by the society and by language experts to determine its suitability to the concerned language. Many of newly coined words are accepted very easily where as some are rejected. Non-experts who dislike the neologism sometimes also use this argument, deriding the neologism as "abuse and ignorance of the language." Some neologisms, especially those dealing with sensitive subjects, are often objected to on the grounds that they obscure the issue being discussed, and that a such word's novelty often leads a discussion away from the root issue and onto a sidetrack about the meaning of the neologism itself. Proponents of a neologism see it as being useful, and also helping the language to grow and change; often they perceive these words as being a fun and creative way to play with a language. In addition, the semantic precision of most neologisms, along with what is usually a straightforward syntax, often makes them easier to grasp by people who are not native speakers of the language (Banjar, 2011).

Neologisms are accepted as parts of the language. Other times, however, they disappear from common use just as readily as they appeared. Whether a neologism continues as part of the language depends on many factors, probably the most important of which is acceptance by the public. If a newly coined word continues to use by the masses, it always eventually sheds its status as a neologism and enters the language even over the rejection of its opponents. 
Abba (2013:118) argues that, politics is one of most productive sources of generating new words. Neologisms in this field often are used to make some political or rhetorical point. And some words are powerful enough to shape peoples attitude towards certain issues.

Mohsin (2013: 821) states that neologism can be a brand new word gaining usage in a language, or a new meaning for a word already in existence. Such a term isn't typically in common use, but may become so if it is used often. Neologisms can come from a variety of places and might be gleaned from scientific or technical language, come from other languages, be derived by putting two words together, or they may be solely invented. Language specialists suggest new words often migrate into a language most with great cultural changes or with the integration of two cultures that speak two different languages.

Furthermore, in support of the above submission, Wurma (2002) believes that, in virtually all languages, words meaning is broadened to encompass new ideas and concepts introduced by speakers. He stress that widening of meaning is a sign of language development. And, virtually in all societies, new ideas, senses and opinions are being created to meet the challenges of modern life.

\section{Coinage and Neologisms in "An ce ka ce" (They said you say)}

According to Martan (2008:75) neologisms are new words that are use in society, and are deemed to have been non-existent in the past. Neologisms are very important in the generative capacity of natural languages; they are the 
elements that make languages living rather than dead..." and "are an indicative of language death".

The slogan used by politicians and presenters of radio political programs in the daily use of like has demonstrated a birth and rebirth of Hausa vocabularies from linguistics perspectives, indeed a breakthrough in expanding the Hausa lexicon. For example words and phrases like:

\section{Hausa}

1. Naka Sai Naka

2. Daram-dam

3. Ka yi mun gani

4. Ta ware

5. Dawo-dawo

6. Ya hau kan Katanga

7. Hannun Jarirai

8. Sabarta Juyata

9. Janar Buzu-Buzu

10. Farfesun Tarugu

11. Amanawan katambaluwa

12. Baba Ojo gwanin rawar banjo

13. Namu duka sabo tumaki

14. Labarum mako

\section{Gloss}

Yours is yours

Unshakable

You did, we saw

To separate

Return-return

He cross a fence

Children hands

Change from one side to other

General with bears.

Soup of pepper

Trustees of Katambaluwa

Father Ojo, master of dance

ours all hold sheep

News week

The Nagarta Radio Hausa Political Program “An ce, ka ce" is a political program the presenters use some words and phrases in the program which are 
meant to hide the actual names of the personalities being referred to, at the same time coined a word or phrase giving a description of those personalities. Here, presenters twist and twill language to suit the purpose and amuse the largest audience.

In relation to the above, some words and phrases are already in the realm and vocabulary of the Hausa language. Eventually due to the advent of modern politics, some of them have taken several connotations as used in the radio political program. They are diverted from the literal traditional meaning and are motivated by the mental representation of the speaker and hearer as well as metaphorical features association to the word which makes it well understood within the domain of politics. With this, we can say coinage and neologism took place in the radio (media).

However, coinage and neologisms can be found in the below data:

\section{Kúrmusàa-kúrmusàa Gloss: Defeat}

Meaning: Yin nasara a kan 'yan hamayya
16. Qákkàvín kavár
Gloss: Destroy
Meaning: Rushewa
17. Shaaranáyè
Gloss: Lie
Meaning: Shara qarya
18. Hántánmantán
Gloss: What was not understand

Meaning: Abin da ba a fahimce shi ba

19. Hadariín tsígèe-tsíigèe Gloss: Cloud of removal

Meaning: Tsige masu riqe da mukamai

20. Yaakice-kice Gloss: Conflict Meaning: Hatsaniya

21. Siibàree-na-báiyee Gloss: Injustice Meaning: Zalunci

22. Shílloríiyà Gloss: Light Meaning: Abu mara nauyi

23. Zuuquii tàa málli Gloss: Lie Meaning: Karya 
24. Bòsórùwaa Gloss: Unserious Meaning: Shìríiritaa

25. Hara da bálliyaa Gloss: Difficult situation

Meaning: Rikitaccen al'amari

26. Hárqumaaquma Gloss: Discomfort Meaning: Baqe-baqe

27. Giríngishìxii da gírgixì Gloss: Meaning: Kujera na rawa

28. Màgúrmàagùxín Gloss: Fraud Meaning: Maguxi

29. Kaafatàni Gloss: Altogether Meaning: Gaba xaya

In the data, one can see how coinage and neologism is in Hausa political program, which results from media, in the sense that the actual word/phrase has been modify to suit the interest of the presenters and to capture the minds of the listeners as well. This enriched Hausa vocabulary, basically the media or the program as effective tools of disseminating changes and diffusion of innovation, which could accelerate the adaptation of Hausa lexical used created by the media. Since, word could be created either deliberately or accidentally without using the word formation processes.

Based on Sani's (2011:92) argument which argues that, coinage ranges from single to multiple words. However, the following are some of their characteristics which the data possessed:

i. Absence of definition of terms,

ii. Only equivalence are provided;

iii. Predominance of translation;

iv. Little use of morphological resources of the language;

v. Resistance to creativity and innovation in coining new terms;

vi. Provision of more than one equivalent to a term; 
vii. Lack of general principles, methodological guidelines and convention governing the selection and adoption of loanword; and

viii. Lack of clear strategy of dissemination of the terms for use in different spheres of human activities.

Coinage as the creation of totally new words or phrases in language, took place as in the above examples. Neologism is associated with the formation of new words that represent ideas, objects and concepts in a language, has took place also. This is in accordance with Rey (1995) who notes that neologism as a lexical unit perceived as recent by language users. $\mathrm{He}$ identifies three core areas of neology: formal, Semantic and Pragmatic neology. Formal neology is a result of application of grammatical rules to the morphology of the language e.g suffixation, pre-ffixation etc. while Semantic neology is a feature found in all neologisms. Pragmatic neology is identified in relation to communication. This means that the neologism is used in a social context depending on its appropriateness in communication.

Neologism passes through three stages as it is in the above data: creation, trial; and establishment. Once it gained widespread usage, it becomes stable. Stability is indicated by appearance in glossaries dictionaries and large corpora. Some of the above lexical or phrases are used by individual in communication, not necessarily in political discourse.

In support of this argument Abba (2013:18) argues that the pre-election campaign with the help of electronic media has opened up a new window in the socio-linguistic land map. The word senses have moved from their primary 
meaning and taken up new shades of meaning. New words are created; the existing ones are lexically expanded and semantically redressed in another sphere of meaning.

\section{CONCLUSION}

Politics is a fertile ground for the use of language to express political thoughts and opinions in the political processes. The language of politics reveals certain peculiarities in the communication process and in context perspective, as well as effective disposition of the recipients. This can be seen in the radio political program as presented above. The primary concern is to ascertain radio contribution towards such changes, which in turn develop Hausa language vocabularies. They contain specified features and served specified functions in the political oval. The role of radio is very important to introduce these new words in the language; a new word is popular by way of radio political program because the program introduces these words. Presenters of the program often coin new expressions to make the program interesting and effective which sometimes results the coinage and if these newly coined words are accepted by the masses, they become the part of the language.

Generally speaking, the paper has addressed issues relating to coinage and neologism in Hausa political program "An ce, ka ce" of radio Nagarta, the voice of unity which helps in language development. One other contribution of this research could be seen relatively to the vocabulary of Hausa language and portrayed how important they are to political preparation. Sometimes these newly form words become the accepted part of the language or disappear from common usage just as readily as they appear. The acceptance by the speakers 
is most important factor of a neologism for being a part of the language. If its speakers continuously use a newly coined word, it gradually enters the language even over the rejection of its opponents but finally in that of the many neologisms created, adapted, mutilated, very few survive.

It's hoped that this paper will draw the attention of more researchers towards finding how Hausa radio political program do contribution towards language development; and consider others morphological processes in the analysis of the collected data not only on radio but on various media outfits.

\section{REFERENCES}

Abba, T (2013) Coinage and Neologism in Kano Politics. Studies in Hausa Language, Literature and Culture. The $1^{\text {ST }}$ Hausa National Conference. CSNL. Kano: Bayero University

Adamu, Y. M (2002) "The Development of Hausa Neologism: Urban Spaces”. In Studies in Hausa Language, Literature and Culture. The Fifth Hausa International Conference. CSNL. Kano: Bayero University.

Balarabe, S (2007) "The Propagandist Role of Language in Industrial Dispute: The Case of Nigerian Labor Congress Strike of June, 2007”. A paper presented at 2007 Annual National Conference, organized by the School of Languages. Zaria: Federal College of Education.

Banjar, Sh. (2011). Neologism and Translation. Retrieved September 26, 2019 from http://www.slideshare.net/dr.shadiabanjar/neologismspresentation 
Bauer, L (1983) English Word-formation, Cambridge: Cambridge University Press.

Crystal, D (1992). An Encyclopaedic Dictionary of Language and languages. Oxford: Oxford University Press.

Crystal, D (1997). A Dictionary of Linguistics and Phonetics (4th Crystal, David (2002). The English Language. 2 nd ed. London: Penguin Books.

Egwi, J. C (2002) “A Theoretical Frame work as a solution to the problems of major and minor languages in Education in multilingual setting like Nigeria". I Oyewole A. (ed) Development of the minority languages in Nigeria. Ondo: Association of Nigerian Languages Teachers (ANLAT).

Fagge, U. U. (2012) Hausa Language and Linguistics. Zaria: ABU Press.

Gabari, A. U (2012) Gudunmuwar gidajen rediyo da suke a jihar Kano ga adabin Hausa. An M.A Hausa Dissertation presented to the Department Nigerian Languages, Bayero University, Kano.

Gandu, G. H (2014) Metaphor, Graphics and Political Identity in Northern Nigeria: The Expressions on Hausa Campaign Posters, Banners and Billboards. FAIS Journal of the Humanities. 79-95

Inuwa, I. M (2017) Misuse of Hausa Language in the Media: Threat to Probable Endangerment. Endangered Languages in Nigeria policy, structure \& Documentation. 1:236 to 251. Kano: University press 
Janssen, M. (2011). Orthographic Neologisms Selection Criteria and SemiAutomatic Detection. Retrieved September 28, 2019 from http:// maartenJanssen web. Net /papers/ neologism.pdf

Katamba, F (1993). Morphology: Modern Linguistics Series. New York: St. Martin's Press.

Kiyawa, A. A. (1983) Language and the Politics of Ethnicity in Nigeria: A Sociolinguistic Perspective. Unpublished M.A Dissertation. University of Wisconsin Madison, USA.

Marten, J (2008). Orthographic Neologisms: Selection Criteria and SemiAutomatic Detection. Lisbon. Portugal

Martin, M. M (2016). Neologisms in Igikuria. Unpublished M.A Project. Department of Linguistics and Languages University of Nairobi-Kenya Mohsin, K (2013) Neologisms in Urdu: A Linguistic Investigation of Urdu Media. Language in India. www.languagein india.com 13(6) 818-826

Mustapha, A. I (2002) Now you see them now you don't: Disappearing Words in Contemporary Hausa. Algaita Journal of Hausa Studies. 2. 1. Kano: Bayero University.

Mukhtar, I. (2004) Introduction to stylistic theories, practice and criticism. 1. Abuja: countryside publishers.

Nasir, A (2008) "Extension and Invention in the Language of Hausa Home Video Industry". Unpublished M.A Thesis. Dept of Nigerian Languages. Kano, Nigeria: Bayero University

Oluseye, A. C (2012) "Language, Media and National Reorientation: A Rhetorical Study of Language Print Media". Ondo: Journal of the School of Languages 6. 2 
Poret, G (2009) where is the origin of language? (unpublished)

Rey, A. (1995). The Concept of Neologism and the Evolution of Terminologies in Individual Languages. In: Sager (ed.) Essays on Terminology. Amsterdam: John Benjamins Publishing. Translation of: L“aménagement de la Néologie. Office de la language française du Québec. January 1975, p. 9-28. University Press.

Rey, A. (1995). Essays on Terminology. J. Benjamins. Toman, J. (1992) Compounding. In Brown, W. (ed.) International Encyclopedia of Linguistics. New York: Oxford University Press.

Sani, S (2011) Language Elaboration: Hausa in $21^{\text {st }}$ Centaury. Studies in Hausa Language, Literature and Culture. The Sixth Hausa International Conference. CSNL. Kano: Bayero University.

Sani, S (2011) Political Language and Hausa Lexical Expansion. Kano, Nigeria: Bench Mark Publishers Limited.

Violeta, J and Jana, J (2015). Conceptional Formation of Neologisms in Various Dictionaries and Primary School Macedonian Language Course Textbooks. Journal of Language and Linguistic Studies 11 (2), 99-116

Wardhaugh, R. (2002). An Introduction to Sociolinguistic, 4th ed. Blackwell Publishers.

Wali, U. A (2013) “An Appraisal of Language and Style of Radio Nagarta's An ce, ka ce". Turunku Journal of Hausa Studies Vol.1 No. 1. Zaria: Federal College of Education. 
Wilson, D. \& D. Sperber, (2004). Relevance Theory. In Horn L, Ward G. (eds). The Handbook of Pragmatic . Blackwell: Oxford

Wurma, A. G (2002) Semantic Changes Occurring in Hausa Language. Algaita Journal of Hausa Studies 2. 1. Kano: Bayero University.

Yule, G. (1996). The Study of Language. (2nd ed). Cambridge: Cambridge University Press.

Zailani, A. A and Muntari, H (2018). An Analysis of Neologism in Hausa Cellular Phone Market. ZAJOLALS 1. 9 School of Secondary Education Languages Federal College of Education, Zaria 